\title{
Procesos gravitacionales-fluviales y preservación de vegetación boscosa en un área volcánica: Formación Rancahué (Oligoceno), Andes neuquinos, Argentina
}

\author{
Luis A. Spalletti ${ }^{1}$, Gonzalo D. Veiga' ${ }^{1}$, Juan R. Franzese ${ }^{1}$ \\ ${ }^{I}$ Centro de Investigaciones Geológicas, CONICET-Universidad Nacional de La Plata, calle $1 N^{o}$ 644, b1900TAC La Plata, Argentina. \\ spalle@cig.museo.unlp.edu.ar; veiga@cig.museo.unlp.edu.ar; franzese@cig.museo.unlp.edu.ar
}

\begin{abstract}
RESUMEN. Depósitos clásticos de la Formación Rancahué (Oligoceno Superior), que constituye parte del registro volcánico y sedimentario de la cuenca oligocena-neógena de Aluminé (Cordillera de los Andes, $70^{\circ} \mathrm{W}$ y $39^{\circ} \mathrm{S}$ ), permitieron analizar los fenómenos de interacción sedimentaria en ambientes volcánicos continentales y caracterizar los mecanismos de preservación de restos de troncos asociados a sucesiones aluviales volcano-sedimentarias. En estos depósitos, se ha identificado un bosque petrificado de tierras altas con 33 ejemplares preservados en posición de vida, con Nothofagoxylon como elemento dominante, desarrollado bajo condiciones climáticas templadas y húmedas. En el área de estudio, la Formación Rancahué se caracteriza por la estrecha interrelación lateral y secuencial entre tres asociaciones de facies. La asociación A se compone de aglomerados y conglomerados gruesos monomícticos (con fenoclastos de basaltos) acumulados en ambientes proximales de altas pendientes (taludes y en el pie de taludes subaéreos) como producto de 'debris floods' o de flujos hiperconcentrados, avalanchas, deslizamientos y flujos de detritos. Estos depósitos tienen procedencia local y se vinculan con un cuerpo volcánico basáltico que generó un importante relieve intracuencal. La asociación B consiste en conglomerados, sabulitas, areniscas conglomerádicas y areniscas gruesas y muy gruesas con variadas estructuras primarias y se asigna a un sistema fluvial con desarrollo regional, baja canalización y carga traccional, con áreas de aporte en la cordillera de los Andes. La asociación C se compone de facies clásticas de textura fina, acumuladas esencialmente por decantación en ambientes subaéreos y subácueos, con el periódico aporte de lluvias de cenizas volcánicas, y con niveles en los que se aprecia la formación de suelos. Los depósitos fluviales incluyen restos de troncos transportados que muestran el poder erosivo de las corrientes de flujo rápido que los acumularon. El bosque petrificado arraigó en depósitos de la asociación de facies $\mathrm{C}$ y quedó preservado en los suprayacentes aglomerados y conglomerados de la asociación A. Se interpreta que los troncos fueron sepultados por los flujos gravitacionales que operaron en abanicos aluviales y coluviales de la zona riparia hidrogeomórfica y que se caracterizan por una tasa de sedimentación alta y un discreto poder erosivo por su naturaleza laminar o quasi laminar.
\end{abstract}

Palabras clave: Depósitos gravitacionales de talud, Depósitos fluviales proximales, Oligoceno, Andes neuquinos, Bosque de tierras altas, Argentina. 


\begin{abstract}
Fluvial-gravitational processes and preservation of forest vegetation in a volcanic area: the Rancahué formation (Oligocene), Neuquén Andes, Argentina. The siliciclastic deposits of the Rancahué Formation (Oligocene, Aluminé Basin), formed in the eastern side of the Andean Cordillera $\left(70^{\circ} \mathrm{W}\right.$ y $\left.39^{\circ} \mathrm{S}\right)$ are studied to evaluate the relationship among different depositional systems in volcanic settings and to disclose the processes that contributed to the preservation of a forest developed at the foot of a volcanic relief. In the alluvial volcano-sedimentary record of the Rancahué Formation an upland petrified forest with $33 \operatorname{logs}$ in life position was identified. This flora, with Nothofagoxylon as the main taxon, was developed under temperate and humid climatic conditions. Three facies associations were defined in the study region. Facies association A was accumulated in subaerial talus and foot-talus slopes, and is composed of monomictic (basaltic) boulder and cobble conglomerates formed by debris floods, hyperconcentrated flows, avalanches, landslides and debris flows. The source of these sediments is local and is related to the growth of an intrabasinal basaltic volcanic edifice. Facies association B consists of cross-stratified, plane bedded and massive conglomerates, pebbly sandstones and coarse-grained sandstones accumulated in a regional braided fluvial system with source areas located in the Andean Cordillera. Facies association $\mathrm{C}$ is characterised by fine-grained sediments accumulated in subaerial and subaqueous environments, with periodic contribution of ash falls and development of palaeosols. The forest rooted in deposits of facies association $\mathrm{C}$, and the logs preserved in life position are located within the overlying coarse-grained volcaniclastic deposits of facies association A. The burial and preservation of this vegetation was favoured by the highly aggrading rhythm and comparative low erosive power of the gravitational flows that operated in alluvial and colluvial fans of the riparian hydrogeomorphic zone. Conversely, abundant transported and broken trunks included in the deposits of facies association B clearly indicate the strong erosive power of the currents of the associated braided fluvial system.
\end{abstract}

Keywords: Talus deposits, Proximal fluvial deposits, Oligocene, Neuquén Andes, Upland petrified forest, Argentina.

\section{Introducción}

El estudio de los procesos sedimentarios en áreas de volcanismo activo ha atraído la atención de los investigadores desde hace largo tiempo (cf. Fisher y Smith, 1991). Este campo del conocimiento científico es de particular interés para comprender las características del paisaje, la tectónica, las alteraciones climáticas, y los procesos de erosión y acumulación en las cuencas sedimentarias donde la actividad volcánica ha tenido un rol preponderante. En este marco, es muy frecuente la actividad de procesos catastróficos sineruptivos, tales como deslizamientos, avalanchas y flujos de detritos (Smith, 1991; Tanner y Hubert, 1991; Brown et al., 2009), considerados de importancia en la evolución de los cuerpos volcánicos (Glicken, 1991; Palmer y Neall, 1991). Uno de los aspectos que también resulta de interés en este contexto de interacción volcánico/sedimentaria es la influencia de estos procesos en la evolución del registro sedimentario de las cuencas, particularmente cuando se produce el crecimiento de edificios volcánicos sincrónico con el proceso de relleno de las cubetas sedimentarias. Las depresiones intermontanas desarrolladas en regiones con volcanismo activo constituyen laboratorios naturales muy apropiados para analizar la interacción entre procesos regionales de sedimentación fluvial y los relacionados con eventos catastróficos sineruptivos. Por otra parte, la recurrencia de procesos de sedimentación episódicos y de muy alta energía en estos ambientes promueve la repetición de eventos de sepultamiento y excepcional preservación de los bosques que colonizan estos ambientes aluviales/fluviales.

Con la finalidad de aportar nuevos conocimientos para la formulación de un modelo conceptual sobre los fenómenos de interacción sedimentaria en ambientes volcánicos continentales y de caracterizar los mecanismos de preservación de restos de troncos asociados a sucesiones aluviales volcano-sedimentarias, se analizan en este trabajo los depósitos clásticos de la Formación Rancahué, que constituye parte del registro volcánico y sedimentario de la cuenca oligocena-neógena de Aluminé, desarrollada en el ámbito de la cordillera de los Andes a los $70^{\circ} \mathrm{W}$ y $39^{\circ} \mathrm{S}$ (Franzese et al., 2011).

\section{Marco Geológico}

La Cuenca de Aluminé es un depocentro cenozoico que se ubica entre las latitudes de $71^{\circ} 16^{\prime} \mathrm{S}$ y $70^{\circ} 40^{\prime} \mathrm{S}$ y los meridianos de $39^{\circ} 00^{\prime} \mathrm{W}$ y $39^{\circ} 23^{\prime} \mathrm{W}$ (Fig. 1). Abarca esencialmente el actual valle del río Aluminé y áreas aledañas. Está flanqueado al oeste por los Andes argentino-chilenos, al este por la Sierra de Catán Lil y hacia el sur la cierra el Alto del Quillén. El sector andino está conformado esencialmente por rocas magmáticas correspondientes tanto al Paleozoico Superior (Complejo Plutónico Huechulafquen) como al batolito cretácico (Grano- 


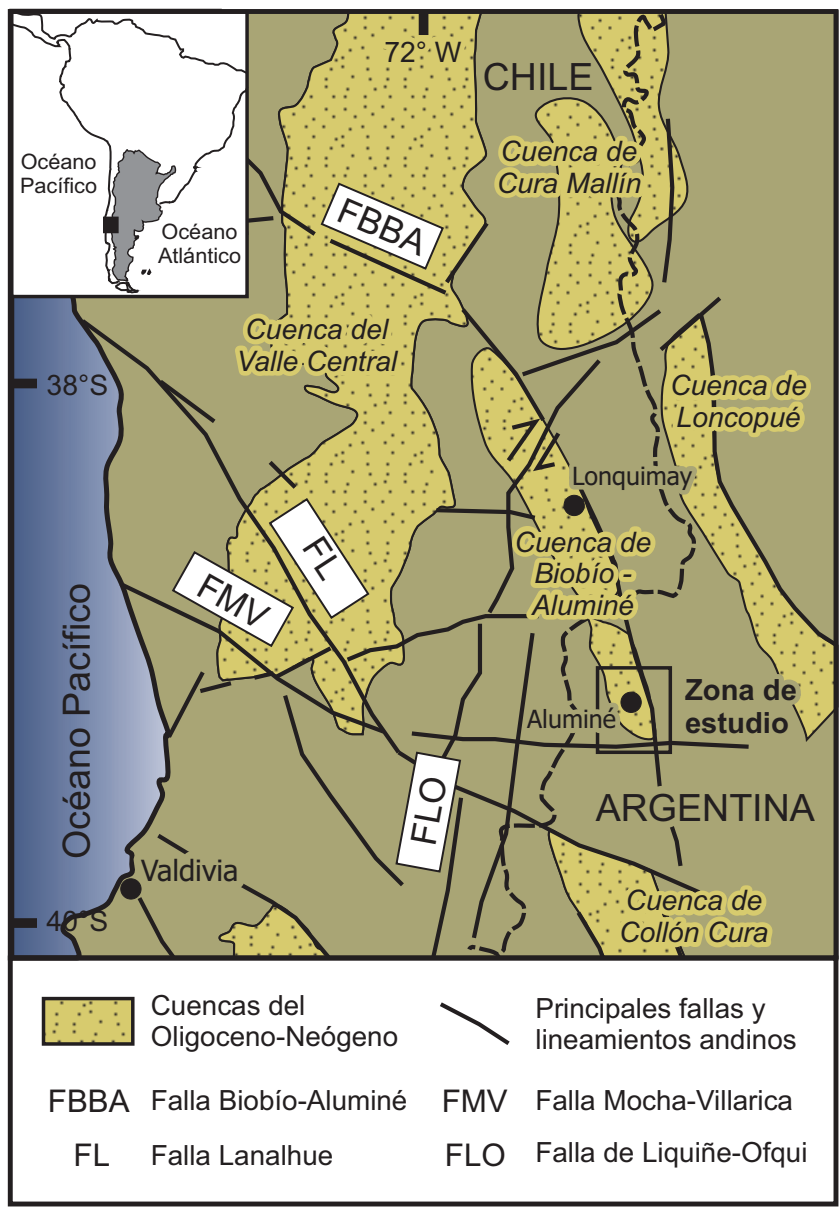

FIG. 1. Cuencas oligocenas y neógenas argentino-chilenas entre las latitudes de $37^{\circ} \mathrm{S}$ y $40^{\circ} \mathrm{S}$ (adaptado de Melnick y Echtler, 2006; Radic, 2010; Franzese et al., 2011).

diorita Paso de Icalma) (Cucchi y Leanza, 2006). El flanco oriental de la cuenca (Sierra de Catán Lil) tiene una constitución geológica compleja en la que participan rocas del basamento ígneo metamórfico del Paleozoico Superior (formaciones Colohuincul, Piedra Santa y Complejo Plutónico del Chachil) y sucesiones volcano-sedimentarias (TriásicoJurásico Medio) que representan al relleno inicial de la Cuenca Neuquina (Cucchi y Leanza, 2006; Franzese et al., 2011). Por su parte, el límite austral de la cuenca está caracterizado por afloramientos de rocas magmáticas gondwánicas del Complejo Plutónico Huechulafquen y de rocas volcánicaspiroclásticas de amplio espectro composicional y que, en el área de estudio, afloran saltuariamente, correspondientes al arco magmático paleógeno (Formación Auca Pan).
El registro de la Cuenca de Aluminé ha sido analizado recientemente por Franzese et al. (2011). Estos autores respetan la nomenclatura formal provista (Turner, 1965, 1973) y seguida por Cucchi y Leanza (2006), pero hacen un nuevo ordenamiento estratigráfico sobre la base de información detallada de campo y nuevos datos geocronológicos. Las unidades que constituyen el relleno de esta cuenca son las formaciones Rancahué, Chimehuín (unidad epi-piroclástica) y el Basalto Tipilihuque (Fig. 2).

La Formación Rancahué ocupa amplias áreas de afloramiento especialmente en los sectores occidental y central de la cuenca (Fig. 3). Alcanza hasta $500 \mathrm{~m}$ de espesor y, según Franzese et al. (2011), se compone de lavas basálticas y depósitos de conglomerados monomícticos matriz sostén y lapillitas escoriáceas clasto sostén (facies R1), 
lapillitas tobáceas matriz sostén (R2), conglomerados macizos matriz sostén con intercalaciones de areniscas y conglomerados finos clasto sostén (R3), areniscas guijarrosas y sabulitas o depósitos clásticos con individuos entre 2 y $4 \mathrm{~mm}$ (R4) y areniscas con intercalaciones de lentes conglomerádicas (R5). Franzese et al. (2011) indican que el registro de la Formación Rancahué está estrechamente relacionado con la falla del río Aluminé (Fig. 3), ya que hacia el oeste de la misma los espesores alcanzan los $500 \mathrm{~m}$, mientras que hacia el este se reducen en forma drástica (menos de $100 \mathrm{~m}$ ) y solo se registran los términos superiores de la unidad, los que apoyan directamente sobre rocas del basamento y se acuñan antes de alcanzar el límite oriental de la cuenca. Dos dataciones con el método Ar/Ar sobre plagioclasas de basaltos ubicados en la parte superior de la Formación Rancahué han dado valores de $25 \pm 1,4$ y $26 \pm 1,5 \mathrm{Ma}$ (Franzese et al., 2011) correspondientes al tope del Oligoceno Tardío (IUGS, 2012). Esta unidad reviste particular interés, ya que en la Formación Rancahué se ha identificado un bosque petrificado con 33 ejemplares preservados en posición de vida.

Franzese et al. (2011) indican que la Formación Chimehuín aflora en el sector oriental de la cuenca, se

\begin{tabular}{|c|c|}
\hline EDAD & $\begin{array}{c}\text { UNIDADES } \\
\text { LITOESTRATIGRÁFICAS }\end{array}$ \\
\hline Pleistoceno-Holoceno & Depósitos aluviales y coluviales \\
\hline & 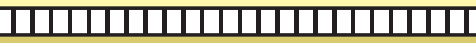 \\
\hline Mioceno Superior & Basalto Tipilihuque/Fm. Chimehuín \\
\hline & 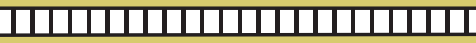 \\
\hline Oligoceno Superior & Fm. Rancahué \\
\hline & 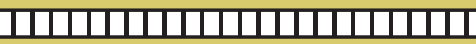 \\
\hline Paleoceno & Fm. Auca Pan \\
\hline & 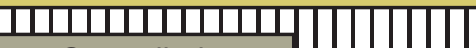 \\
\hline Cretácico & $\begin{array}{l}\text { Granodiorita } \\
\text { Paso de } \\
\text { Icalma }\end{array}$ \\
\hline & 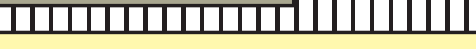 \\
\hline Jurásico Inferior & Fm. Los Molles \\
\hline $\begin{array}{c}\text { Jurásico Inferior } \\
\text { Triásico }\end{array}$ & Fm. Aluminé \\
\hline & 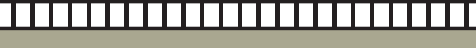 \\
\hline Paleozoico Superior & $\begin{array}{c}\text { Complejos Plutónicos } \\
\text { Chachil y Huechulafquen } \\
\text { Fms. Colohuincul-Piedra Santa }\end{array}$ \\
\hline
\end{tabular}

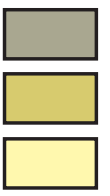

Unidades Intrusivas y Metamórficas

Unidades Volcánicas-Sedimentarias

Unidades Sedimentarias

FIG. 2. Estratigrafía de la región de Aluminé. Información adaptada de Turner (1965, 1973); Cucchi y Leanza (2006) y Franzese et al. (2011). 


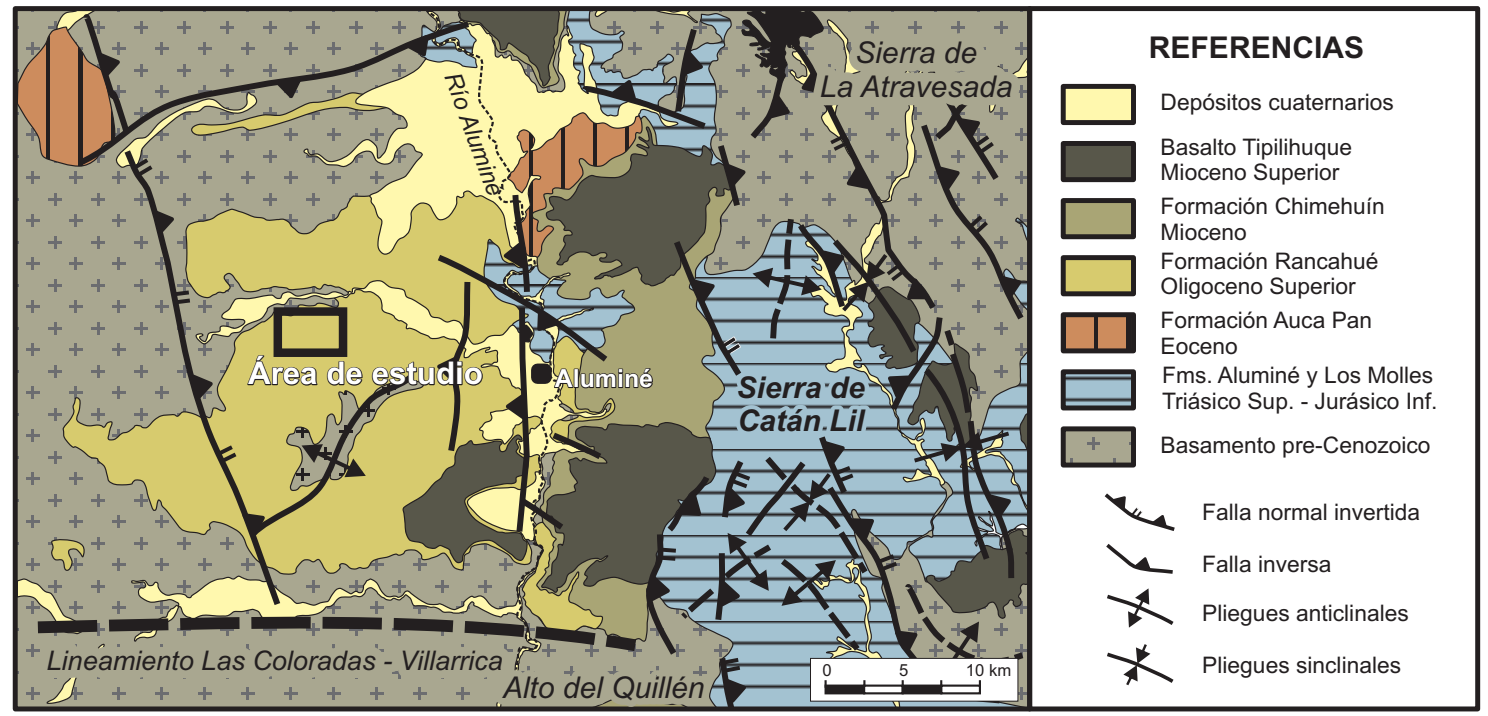

FIG. 3. Mapa geológico de la región de Aluminé y adyacencias (tomado de Franzese et al., 2011).

apoya en discordancia sobre la Formación Rancahué y se acuña rápidamente hacia el oeste (Fig. 3). Se compone de dos facies: areniscas guijarrosas masivas o con estratificación difusa e intercalaciones conglomerádicas (facies $\mathrm{C} 1$ ) y conglomerados clasto sostén con estratificación horizontal y areniscas entrecruzadas con intercalaciones de limolitas y areniscas finas masivas (C2). Por su parte, el Basalto Tipilihuque no solo aparece con preferencia en el sector oriental de la cuenca, donde cubre en forma concordante a depósitos de la Formación Chimehuín, sino que también se registra en los bloques elevados de la Sierra de Catán Lil y áreas vecinas en las que yace directamente sobre rocas del basamento (Fig. 3). Se trata de lavas basálticas olivínicas con espesores de hasta $10 \mathrm{~m}$. Estas volcanitas han sido datadas con el método ${ }^{40} \mathrm{Ar} /{ }^{39} \mathrm{Ar}$ en plagioclasa en 9,4 $\pm 0,7 \mathrm{Ma}$ (Franzese et al., 2011). Por tanto, el Basalto Tipilihuque se asigna al Mioceno Tardío, mientras que, por su posición estratigráfica, la Formación Chimehuín se habría acumulado durante el Mioceno.

En su trabajo sobre la Cuenca de Aluminé, Franzese et al. (2011) concluyen que el registro volcano-sedimentario se produjo en dos etapas, una extensional del Oligoceno, caracterizada por aportes volcánicos procedentes del sector andino (Formación Rancahué) y otra contraccional del Mioceno (Formación Chimehuín y Basalto Tipilihuque), en la que los depósitos constituyen el relleno de una cubeta intramontana, provienen desde el este y quedan limitados por relieves elevados, debido a la inversión de estructuras extensionales mesozoicas.

\section{Materiales y métodos}

Las tareas de campo se desarrollaron en un área con excelentes afloramientos de la Formación Rancahué ubicada a los $39^{\circ} 13^{\prime} 34^{\prime \prime}$ 'S y $70^{\circ} 58^{\prime} 12^{\prime \prime} \mathrm{W}$, muy cercana a la ruta provincial 18 que une el pueblo de Aluminé con la localidad de Ruca Choroy, en el oeste de la provincia del Neuquén (Fig. 3). El estudio detallado de los términos volcanoclásticos de la Formación Rancahué se realizó a partir del relevamiento de dos perfiles de detalle (Fig. 4), los que permitieron definir las facies sedimentarias (a partir de la textura, composición y estructuras sedimentarias que caracterizan a los distintos estratos) y las correspondientes asociaciones de facies. Estos perfiles corresponden a exposiciones parciales de la Formación Rancahué, las que alcanzan entre 30 y $40 \mathrm{~m}$ de espesor, pero en las que los cuerpos de roca se pueden seguir por varios centenares de metros, por lo que fue posible también efectuar su análisis arquitectural bidimensional. Dicho estudio arquitectural se realizó a partir de paneles y fotomosaicos de las excelentes exposiciones, sobre los que se trazaron las superficies limitantes de los litosomas y se incorporaron las asociaciones de facies identificadas. Los perfiles sedimentológicos y los 

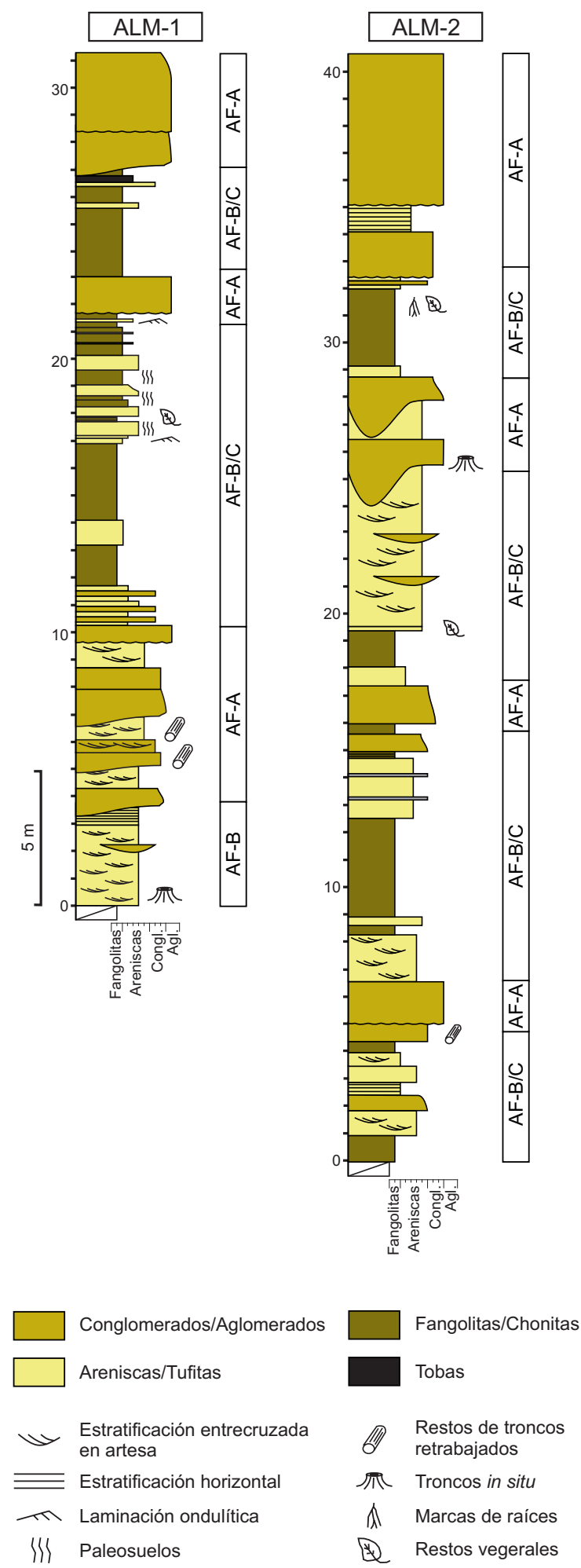

FIG. 4. Perfiles sedimentológicos de la Formación Rancahué, relevados en el área de estudios. AF-A, AF-B y AF-C: asociaciones de facies A, B y C, respectivamente. 
estudios arquitecturales fueron empleados para establecer los sistemas de depositación a escala regional. Estas tareas se complementaron con el muestreo de areniscas y fangolitas epi-piroclásticas.

\section{Análisis de facies}

En la Formación Rancahué se definió un total de 16 facies sedimentarias, cuyas características principales se muestran en la tabla 1. Todas las facies reconocidas son clásticas, varias de ellas volcanoclásticas, tanto primarias como reelaboradas, y comprenden un amplio rango textural desde aglomerados hasta fangolitas (Fig. 4).

Sobre la base de la distribución de las facies sedimentarias identificadas, se pudieron definir para la Formación Rancahué, en la región de estudio, tres asociaciones de facies (Tabla 1; Fig. 4). Estas asociaciones se diferencian por su textura, composición, por la geometría externa de los litosomas y por su organización interna. Las mismas no muestran una clara organización en sentido estratigráfico, ya que se caracterizan por un diseño de superposición alternante (Fig. 4). Representan condiciones de acumulación contrastantes en un ambiente de depositación netamente continental.

\subsection{Asociación de facies A}

\subsubsection{Descripción}

Caracterizada por la presencia de dos facies (F1 y F2, Tabla 1) de aglomerados (depósitos constituidos por bloques de más de $256 \mathrm{~mm}$ de tamaño medio) y conglomerados gruesos (compuestos por individuos entre 64 y $256 \mathrm{~mm}$ ), ambos con composición monomíctica (fenoclastos de basaltos). La asociación constituye cuerpos potentes, entre 1,5 y $5 \mathrm{~m}$ de espesor. Los bloques basálticos pueden superar $1 \mathrm{~m}$ de diámetro (Fig. 5a).

Los depósitos de la facies F1 son clasto soportados, los individuos son angulosos hasta redondeados y poseen matriz tobácea, posiblemente infiltrada (Fig. 5b). Sus cuerpos son internamente macizos y pueden mostrar una grosera gradación, tanto normal como inversa (Fig. 5c).

Por su parte, los aglomerados y conglomerados que constituyen la facies F2 son matriz soportados y se componen de clastos angulosos y subangulosos, mal seleccionados y con distribución caótica (Fig. 5d). Los depósitos muestran una mucho más marcada tendencia a la tabularidad y por tanto poseen una buena continuidad lateral. Una característica saliente en ambas facies es que con frecuencia contienen fenoclastos y bloques sobredimensionados (de hasta $1 \mathrm{~m}$ de diámetro) tanto en el interior como en el tope de los cuerpos (Fig. 5d).

\subsubsection{Interpretación}

Esta asociación de facies es el resultado de la acumulación por flujos gravitacionales en ambientes muy proximales de altas pendientes (Brown et al., 2009). La naturaleza monomíctica, basáltica que poseen los aglomerados y conglomerados de esta asociación, indica una procedencia local, desde áreas con relieve volcánico intracuencal.

La facies F1 se interpreta como el depósito de 'debris floods' o de flujos hiperconcentrados que tienen un comportamiento Newtoniano-No Newtoniano y en los que todo el material sufre movilización, pero en el que la mezcla de detritos no es completa (Wilford et al., 2005). La geometría lenticular de los depósitos de la facies $\mathrm{F} 1$ pone de manifiesto que los sedimentos se acumularon en áreas canalizadas del talud, ubicadas pendiente arriba del pie del relieve volcánico.

La facies F2 se considera el resultado de la acumulación por avalanchas, deslizamientos y flujos de detritos (Ui, 1983; Palmer et al., 1991; Brown et al., 2009) que tienen comportamiento No Newtoniano, poseen alta concentración de material sólido y en los que la mezcla sedimento-agua es completa (Wilford et al., 2005).

Se puede considerar que estos depósitos de carácter muy proximal se formaron en los taludes y en el pie de taludes (Tanner y Hubert, 1991; Brown et al., 2009) o en los que Wilford et al. (2005) denominan abanicos aluviales y coluviales tributarios a valles angostos y de fuerte pendiente. Su desarrollo sincrónico con fenómenos eruptivos ha sido destacado por diversos autores (cf. Reubi et al., 2005; Brown et al., 2009). También se deduce que la generación de estas tan peculiares facies está vinculada a una región de clima templado, tal como lo sugiere la existencia de una flora de tierras altas ('upland forest', Brown et al., 2009) constituida por árboles de taxones variados y de grandes dimensiones (Wilford et al., 2005; Brea et al., 2009). Estas áreas de piedemonte fueron las vías de desagüe de agentes hidrogeomórficos (Wilford et al., 2005), del tipo de los flujos de detritos, 'debris floods' y avalanchas de detritos. Estos agentes operaron en áreas constituidas por vegetación boscosa, por lo que se 
TABLA 1. FACIES SEDIMENTARIAS IDENTIFICADAS EN LOS DEPÓSITOS DE LA FORMACIÓN RANCAHUÉ EN EL ÁREA de ESTUdio. PRINCIPALES CARACTERÍSTICAS E INTERPRETACIÓN DINÁMICA ELEMENTAL.

\begin{tabular}{cccc}
\hline $\begin{array}{c}\text { Asociación } \\
\text { de facies }\end{array}$ & Facies & Litología & Estructura \\
\hline
\end{tabular}

F1 Conglomerado grueso y aglomerado monomíctico Maciza hasta con grosera (basáltico), clastosoportado, clastos angulosos a re- gradación normal e inversa. dondeados, matriz tobácea (posiblemente infiltrada).
Depósitos de debris floods o de flujos hiperconcentrados Newtonianos-No Newtonianos.

AF-A

F2 Conglomerado grueso y aglomerado monomíctico Maciza.

Depósitos No-Newtonianos de(basáltico), clastos angulosos y subangulosos, caóticos, matriz soporte. bido a avalanchas, deslizamientos y flujos de detritos.

F3 Sabulita a conglomerado grueso (polimíctico), clastosoportado, individuos subredondeados.

Sabulita a conglomerado grueso (polimíctico), clasto- Estratificación plana. soportado, individuos subredondeados.

F5 Sabulita a conglomerado grueso (polimíctico), clastosoportado, individuos subredondeados.

F6 Sabulita a conglomerado grueso (polimíctico), clastosoportado, individuos subredondeados.

F7 Arenisca conglomerádica.

AF-B

F8 Arenisca conglomerádica.

F9 Arenisca conglomerádica.

F10 Arenisca gruesa y muy gruesa.

F11 Arenisca gruesa y muy gruesa, tobácea.
Maciza hasta con gradación normal.

Depósitos del núcleo de barras longitudinales.

Depósitos de capa plana de alto régimen de flujo.

Estratificación de bajo ángulo.

Depósitos traccionales de la transición entre bajo y alto régimen de flujo.

Estratificación entrecruzada Depósitos de progradación fronen artesa.

Estratificación plana.

Estratificación de bajo ángulo.

Depósitos de progradación fron-
tal de barras medias y/o de megaóndulas tridimensionales.

Depósitos de capa plana de alto régimen de flujo.

Depósitos traccionales de la transición entre bajo y alto régimen de flujo.

Estratificación entrecruzada Depósitos de megaóndulas transen artesa. versales a linguoides, régimen de flujo bajo superior.

Estratificación de bajo ángulo.

Depósitos de transición entre bajo y alto régimen de flujo $\mathrm{y} / \mathrm{o}$ de la base de megaóndulas 3D.

Estratificación entrecruzada Depósitos de megaóndulas transen artesa. versales a linguoides, régimen de flujo bajo superior.

F12 Arenisca fina a mediana, tobácea, matriz soportada.

F13 Arenisca fina a mediana, tobácea.

AF-C

F14 Tufita fina a mediana.

F15 Limonita, fangolita, chonita.

F16
Maciza bioturbación.

Estructura ondulítica (óndulas asimétricas).

Maciza bioturbación.

Maciza, estructuras radiculares.

Maciza.
Posibles depósitos traccionales afectados por procesos pedogenéticos.

Depósitos producidos por migración de óndulas de corrientes.

Depósitos de retrabajo hidráulico de depósitos piroclásticos de caída.

Depósitos de decantación suspensiva. Procesos pedogenéticos. 

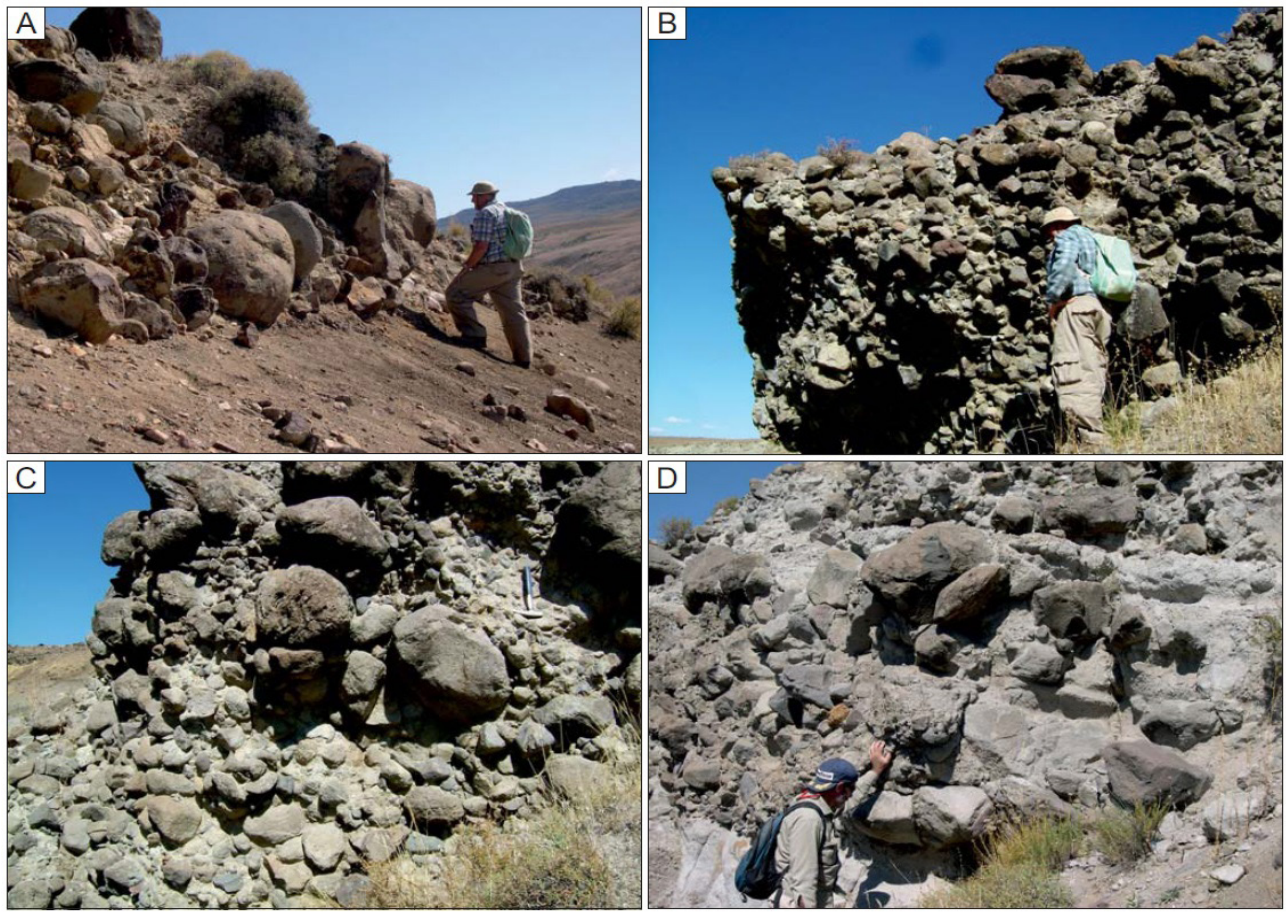

FIG. 5. Asociación de facies A de la Formación Rancahué. A. Depósitos de aglomerados con grandes bloques de basaltos (Facies F1); B. Depósitos de aglomerados clasto soportados, macizos y con individuos de basaltos angulosos hasta subredondeados; C. Cuerpo de aglomerados basálticos con grosera gradación inversa; D. Depósitos de aglomerados matriz soportados y con distribución caótica de los bloques, correspondientes a la facies F2.

interpreta que generaron depósitos en la llamada zona riparia hidrogeomórfica (Wilford et al., 2005). En tal contexto, los procesos de transporte de los materiales se pueden relacionar no solo con áreas de alto gradiente, sino también con la presencia de regolitos o áreas de aporte con lavas en bloques, fuertes precipitaciones pluviales, procesos erosivos intensos e incluso procesos de inestabilización por acción tectónica (Nemeth y Cronin, 2007; Brown et al., 2009).

En este marco, la presencia de vegetación pudo afectar la circulación de las corrientes, con la generación de un relieve erosional (Fig. 6) en el sector de barlovento del obstáculo (Allen, 1973).

\subsection{Asociación de facies B}

\subsubsection{Descripción}

Esta asociación de facies se compone de depósitos de textura gruesa (conglomerados, sabulitas, areniscas conglomerádicas y areniscas gruesas y muy gruesas) y composición polimíctica, en la que participan esencialmente de rocas volcánicas y plutónicas (facies F3-F11, Tabla 1). Desarrollan capas con estratificación entrecruzada en artesa, estratificación de bajo ángulo y plana (Fig. 7a, b). Algunos cuerpos gravosos son internamente macizos y pueden mostrar estratificación gradada normal (Facies F3).

Esta asociación se caracteriza por constituir sucesiones de entre 1 y $5 \mathrm{~m}$ de espesor, con base erosiva y desarrollo lateral muy continuo. Los depósitos incluyen restos de troncos transportados tanto de pequeño como de gran porte (en especial en las facies F6 y F9) y muy esporádicos restos de huesos de mamíferos. Los ejes de las estructuras en artesa se orientan en direcciones WNW-ESE y NNW-SSE.

\subsubsection{Interpretación}

Los depósitos de esta asociación de facies se caracterizan por su textura variada (conglomerados, areniscas conglomerádicas y areniscas gruesas y muy gruesas) con textura clastosoportada y relativamente buena selección. La asociación de estructuras primarias (estratificación en artesa, capas entrecruzadas de bajo ángulo y capas planas) refleja mecanismos de transporte tractivos en condiciones de régimen 


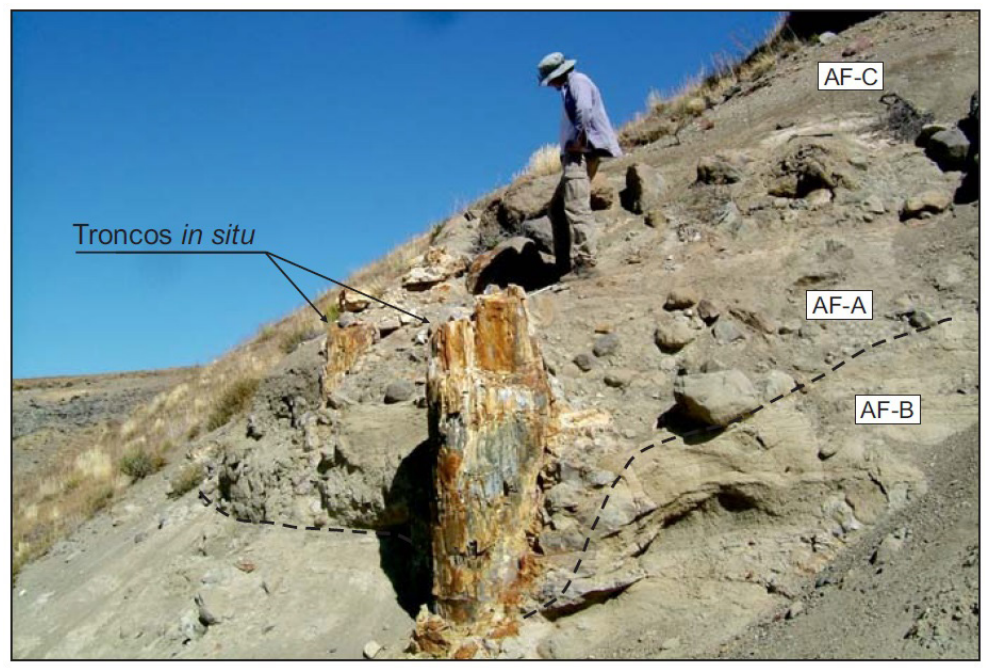

FIG. 6. Vista de troncos preservados en posición de vida incluidos en depósitos de la asociación de facies A (AF-A). Nótese la geometría erosiva de los depósitos gruesos en la zona de contacto con los troncos.
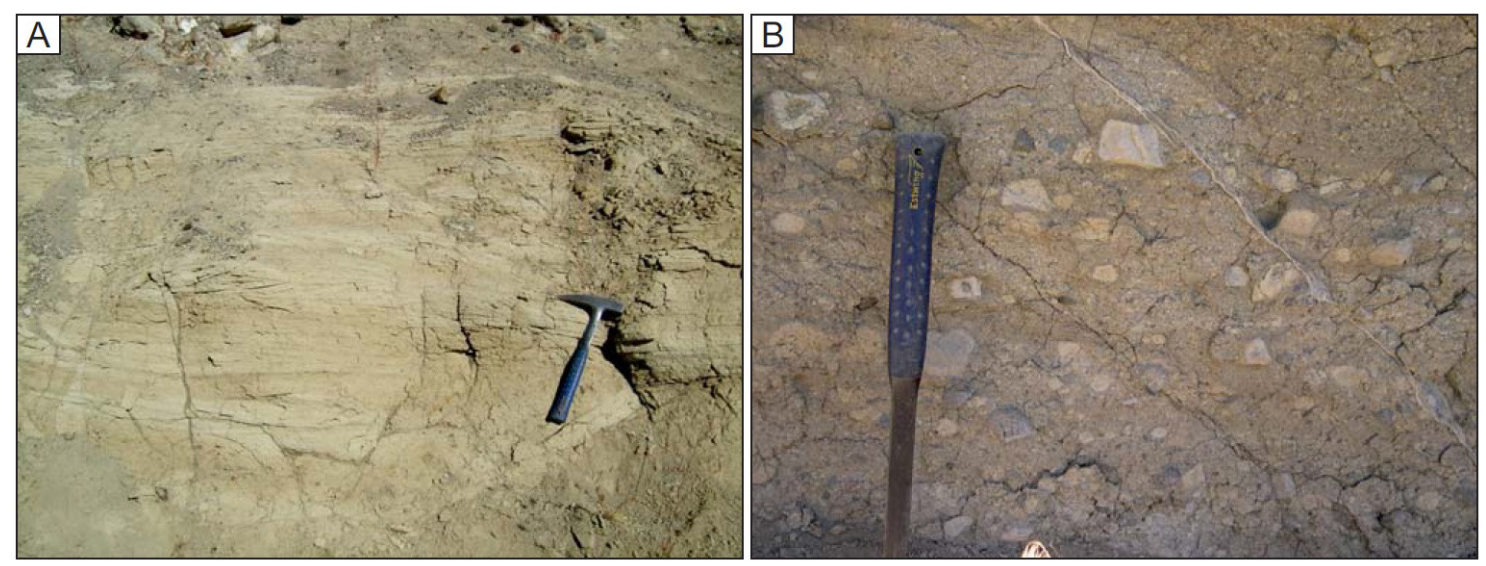

FIG. 7. Asociación de facies B de la Formación Rancahué: A. Areniscas gruesas y muy gruesas con estratificación entrecruzada en artesa; B. Conglomerados y sabulitas de composición polimíctica en capas con estratificación plana y de bajo ángulo.

de flujo bajo hasta alto (Blair y McPherson, 1994). Los depósitos con estructura macizas son característicos del núcleo de barras longitudinales (Lunt et al., 2004; Lunt y Bridge, 2004), mientras que las capas entrecruzadas resultan esencialmente de la progradación frontal de barras medias (Mader y Redfern, 2011). Los niveles con capas planas reflejan posiblemente aguas someras (tope de barras y fenómenos de desbordamiento) (Blair y McPherson, 1994; Brown et al., 2009). Todas estas características son típicas de ríos y corrientes de flujo rápido en los que predominan el transporte y la acumulación de carga de lecho (Schumm, 1981, 1985) asignados a sistemas entrelazados (cf. Smith,
1970; Miall, 1978; Bluck, 1979; Steel y Thompson, 1983; Ramos et al., 1986; Smith, 1990; Bristow y Best, 1993; Bristow, 1993).

La característica geometría mantiforme de los depósitos de esta asociación de facies refleja el desarrollo de un sistema fluvial con canales altamente inestables, importante agradación por acumulación de carga de lecho y súbitos procesos de relocalización lateral de los cauces (Bridge, 2003; Best et al., 2003; Leleu et al., 2010). Este sistema fluvial ha tenido un importante desarrollo regional, tal como lo refleja la naturaleza extracuencal y polimíctica de los depósitos que han sido provistos desde áreas positivas ubicadas al oeste de la cuenca (cordilleranas). 


\subsection{Asociación de facies $C$}

\subsubsection{Descripción}

Los cuerpos de la asociación C constituyen niveles entre $1,5 \mathrm{~m}$ y poco más de $5 \mathrm{~m}$ de espesor, poseen geometría tabular y son regionalmente continuos. Están dominados por limolitas, fangolitas y chonitas (piroclastitas de grano muy fino) de diversas tonalidades (verdosas, ocres y gris oscuras, estas últimas con alto contenido orgánico), a las que se asocian capas delgadas y medianas de areniscas finas y medianas macizas y ondulíticas (facies F12 y F13), tufitas (F14) y tobas vitrocristalinas macizas y con textura porfírica (F16). En las fangolitas es común la presencia de guías de óxidos de manganeso y hierro (estructuras 'slickensides'), bioturbación por desarrollo de raicillas y -en los niveles altamente orgánicos- restos de hojas carbonizados y bastante desarticulados.

Vale destacar que en las sucesiones constituidas por los depósitos de esta asociación de facies pueden también identificarse capas discretas tabulares a lobuladas de hasta $0,6 \mathrm{~m}$ de espesor, formadas por conglomerados de las facies F1 y F2.

\subsubsection{Interpretación}

Estas sucesiones de grano fino, dominadas por rocas pelíticas, constituyen acumulaciones de ambientes de baja energía. Así, no todos los procesos sedimentarios acaecieron en zonas con importante pendiente, sino que hubo períodos en los que la sedimentación en la cuenca de Aluminé se produjo en áreas de bajo gradiente.

Las limolitas y fangolitas son depósitos de decantación a partir de suspensiones, generados tanto en planicies subaéreas (acumulaciones de tipo loéssico) como en cuerpos de aguas estancadas (cf. White y Riggs, 2001). En estas facies se identificaron diversos restos microfosilíferos, tales como palinomorfos, fitolitos, espículas de esponjas y diatomeas (Brea et al., 2007). Los depósitos de areniscas y de piroclastitas reelaboradas (tufitas y tufolitas, ver Teruggi et al., 1978) son resultado de procesos de retrabajamiento por corrientes de baja energía. Los estratos internamente macizos, tanto de fangolitas como de areniscas, han estado sujetos a procesos de bioturbación por plantas y organismos de hábitat edáfico. El desarrollo de suelos está también sugerido por el desarrollo de estructuras de tipo 'slickenside' y por restos de frondas de vegetación arbórea, principalmente de fagáceas (Brea et al., 2007).

Por su parte, la presencia de depósitos piroclásticos de caída, así como la abundancia de material piroclástico retrabajado (tufitas y tufolitas) indica fenómenos de volcanismo explosivo contemporáneos con la sedimentación.

\section{El bosque petrificado de la Formación Rancahué}

En el área de estudio se ha encontrado un bosque petrificado con 33 troncos in situ preservados en los depósitos de la Formación Rancahué. Según Brea et al. (2009) se trata de una paleocomunidad constituida por Nothofagaceae, Cunoniaceae, Myrtaceae, Eucryphiaceae, Atherospermathaceae y Rutaceae, con Nothofagoxylon como el elemento dominante. En el mencionado estudio se ha determinado que el $84 \%$ de los 33 troncos identificados posee diámetros entre $12-102 \mathrm{~cm}$ y que los árboles se distribuían en grupos y se encontraban entremezclados. El bosque tenía una densidad media de 423 árboles/ha con un área basal total de $158 \mathrm{~m}^{2} /$ ha y estaba conformado por dos estratos arbóreos, uno superior $(15-20 \mathrm{~m})$ y otro inferior (7-15 m), con un 16\% de emergentes mayores de $25 \mathrm{~m}$. Desde el punto de vista paleoclimático, se trata de un bosque mixto desarrollado bajo condiciones templadas y húmedas, con una temperatura media anual de $13,71^{\circ} \mathrm{C} \pm 1,7^{\circ} \mathrm{C}$ (Brea et al., 2009).

Los troncos preservados afloran en niveles de aglomerados y conglomerados monomícticos correspondientes a la asociación de facies A(Fig. 6). Los troncos tienen un desarrollo vertical de varios metros y -si bien se encuentran en niveles de la asociación de facies A- se aprecia que pasan verticalmente a las otras asociaciones de facies (Fig. 6). Los árboles han arraigado en depósitos de grano fino de la asociación de facies $\mathrm{C}$ y esto está demostrado por el ensanchamiento basal de los troncos y por la preservación de estructuras radiculares cuando estos aparecen en niveles de grano fino. Contrariamente, cuando se los identifica en la asociación de facies A tienen una morfología uniformemente cilíndrica que revela que han sido soterrados por estos depósitos de aglomerados y conglomerados gruesos (troncos enterrados, Wilford et al., 2005). Importantes cicatrices en los troncos de estos árboles se deben a fenómenos de abrasión de bloques y de troncos removilizados por agentes hidrogeomórficos. 


\section{Arquitectura depositacional}

En el área de estudios, la Formación Rancahué muestra un complejo arreglo de facies. No obstante, las asociaciones de facies aparecen claramente definidas, tanto en los perfiles relevados (Fig. 4) como en su desarrollo regional (Fig. 8).

Los cuerpos de la asociación de facies A se apoyan sobre una marcada discontinuidad erosional que es labrada sobre depósitos de las otras dos asociaciones de facies (Figs. 6, 8). Estos litosomas de gruesos conglomerados y aglomerados poseen una característica lenticularidad y la relación ancho/profundidad, que varía entre 3 y 20 , indica la presencia de cuerpos de extensión reducida (marcadamente acanalados) hasta niveles con importante continuidad lateral (Fig. 8). También es común el desarrollo de estructuras de canal -en- canal (Fig. 9).

Por su parte, los intervalos de las asociaciones de facies B y C muestran importante extensión lateral (Fig. 8). Los de la primera poseen bajo grado de canalización (Figs. 8,9) y se caracterizan por la alternancia de depósitos traccionales (carga de lecho) de alto y bajo régimen de flujo. Los de la segunda están dominados por sedimentitas de grano fino, a las que se subordinan capas discretas de areniscas y piroclastitas primarias y retrabajadas.
Vale destacar que en algunos niveles se aprecian pasajes laterales entre las asociaciones de facies de sistemas fluviales de carga traccional con baja canalización (AF-B) y de planicies dominadas por procesos de decantación suspensiva (AF-C; Fig. 8), aunque la naturaleza detallada de dicha transición no se ha podido registrar en estos afloramientos. Con todo, la presencia de ambas asociaciones en los mismos niveles estratigráficos indica la coexistencia de las redes de drenaje fluviales y las planicies en las que alternaron procesos de desbordamiento fluvial y de decantación a partir de suspensiones eólicas.

\section{Modelo de acumulación}

En el área de estudios, la Formación Rancahué se caracteriza por la interacción de dos contrastantes sistemas de depositación, uno de carácter regional y otro de carácter local (Fig. 10).

El sistema de depositación regional está constituido por las asociaciones de facies B y C. La asociación de facies B muestra depósitos fluviales de carga traccional y baja canalización, formados en una red imbrífera integrada, en la que los materiales detríticos eran transportados desde áreas de aporte, ubicadas en la cordillera de los Andes; estos depósitos testimonian la existencia de valles amplios

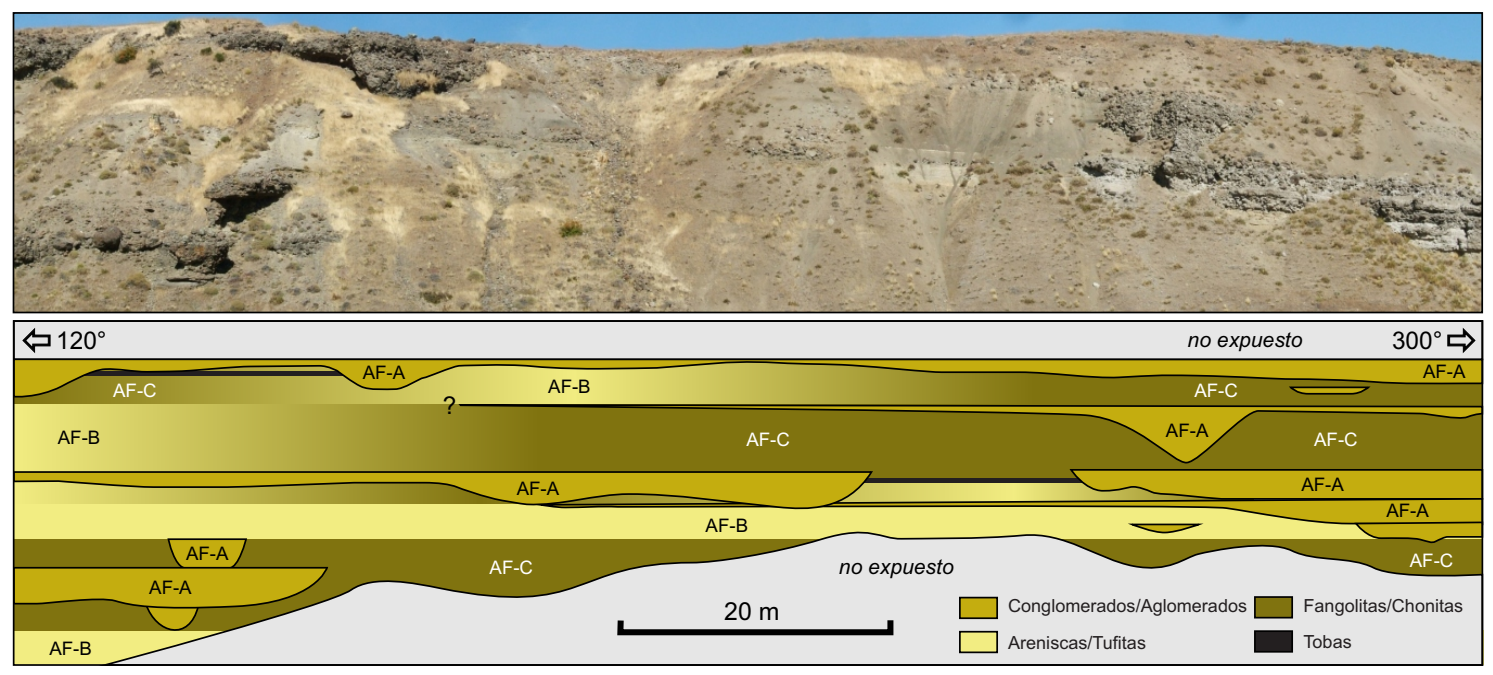

FIG. 8. Arquitectura y diseño de superposición de gran escala de las asociaciones de facies de la Formación Rancahué. Nótese la contrastante geometría de la asociación de facies A, con cuerpos de geometría lenticular, y los mucho más continuos de las Asociaciones de Facies B y C, los que -a su vez- muestran pasajes laterales entre sí. AF-A, AF-B y AF-C: asociaciones de facies A, B y C, respectivamente. 
desarrollados en áreas de importante gradiente. Tanto en sentido lateral como vertical se produjo la acumulación de sedimentos de grano fino de la asociación de facies $\mathrm{C}$, en su mayor parte formados en planicies subaéreas con desarrollo de suelos y en cuerpos de agua estancada. En estos depósitos fue importante el aporte de materiales piroclásticos finos (ceniza y polvo volcánico) procedentes de explosiones volcánicas sincrónicas con la sedimentación. Incluso tampoco debe descartarse la posible existencia de caídas piroclásticas contemporáneas con la acumulación de las asociaciones de facies $\mathrm{A}$ y $\mathrm{B}$, aunque en ese caso los depósitos finos habrían sido totalmente erosionados.

Por su parte, el sistema de depositación local está formado por los depósitos de aglomerados y conglomerados gruesos de composición monomíctica de la asociación de facies A (Fig. 10). Estos sedimentos muy proximales tienen procedencia local y se vinculan con un cuerpo volcánico de composición netamente basáltica, que generó un importante relieve intracuencal. Los depósitos fueron el producto de avalanchas,
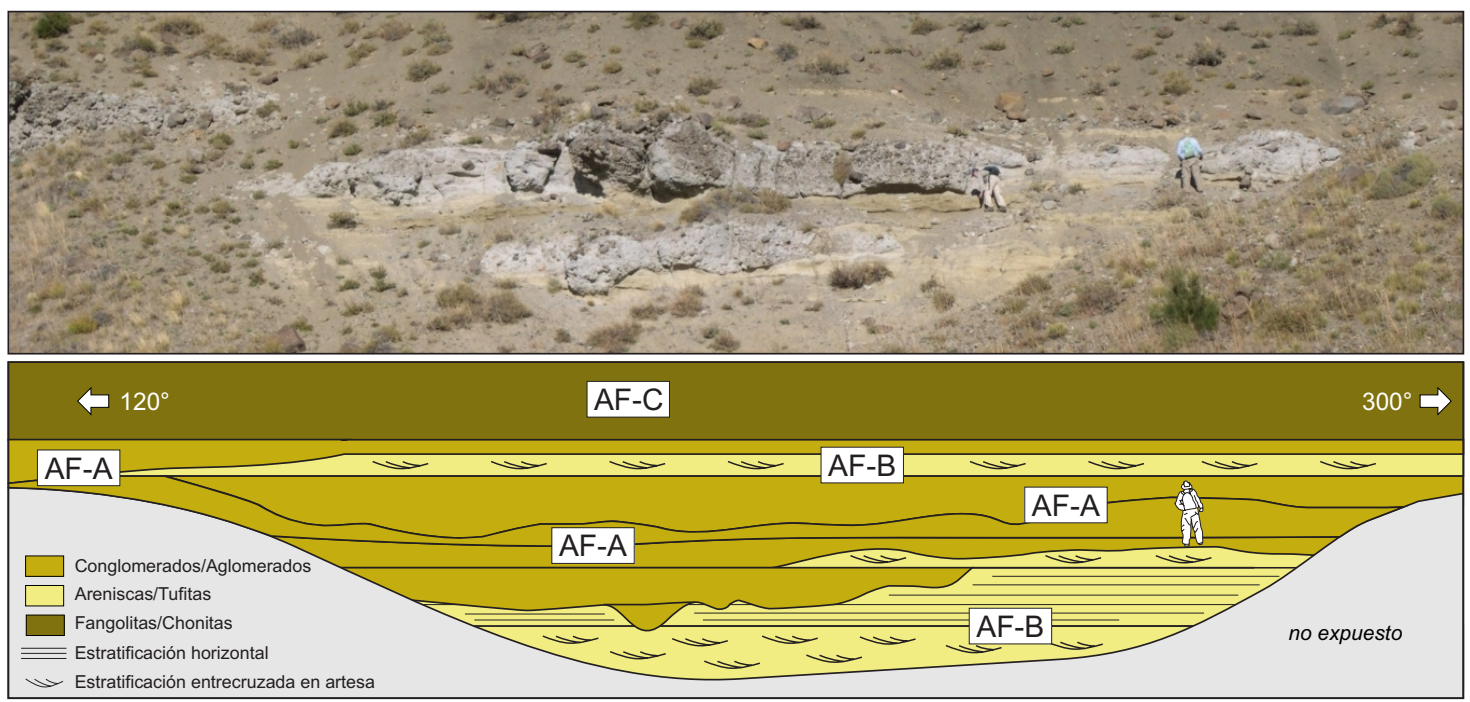

FIG. 9. Panel fotográfico que muestra la arquitectura interna confinada de la asociación de facies A y su relación de marcado contraste con las Asociaciones de Facies B y C. AF-A, AF-B y AF-C: asociaciones de facies A, B y C, respectivamente.

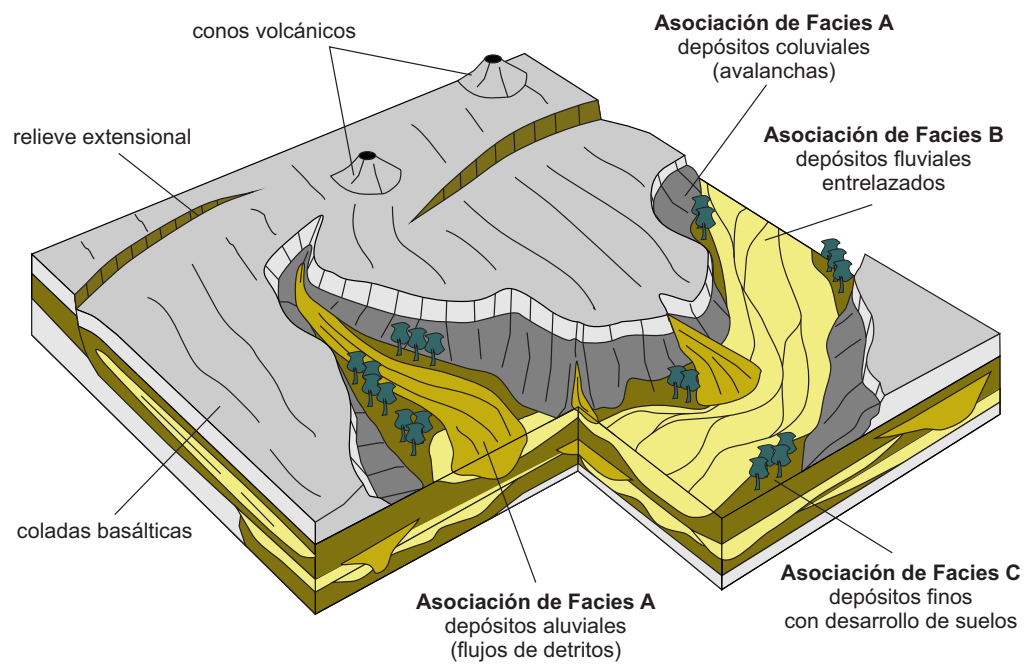

FIG. 10. Modelo de acumulación para los depósitos de la Formación Rancahué. 
flujos de detritos y flujos hiperconcentrados, y se desarrollaron sobre superficies marcadamente erosivas labradas en depósitos del sistema de depositación regional. Estos procesos son característicos de los aparatos volcánicos en escudo, en los que resultan frecuentes los fenómenos de colapso (Moore et al., 1995; Masson et al., 2002)

La interposición de cuerpos de ambos sistemas de depositación indica que los materiales de la asociación de facies A fueron prácticamente 'volcados' o 'vertidos' sobre los del sistema fluvial integrado y los de las planicies, y se desarrollaron sobre cicatrices erosionales labradas al pie de los taludes del relieve volcánico intracuencal (Fig. 10). Estas áreas de interacción entre tan contrastantes procesos sedimentarios se ubicaban en la zona riparia hidrogeomórfica, en la que se asentó un bosque mixto pluriespecífico, formado en condiciones húmedas y templadas.

Los importantes cambios observados en el estilo de sedimentación y específicamente la irrupción de los depósitos gruesos de la asociación de facies A, se relacionan con fenómenos de colapso en el relieve volcánico intracuencal debido a procesos de inestabilidad tectónica, como por ejemplo fallamiento y/o fenómenos sísmicos relacionados con ascenso de magmas en el cuerpo volcánico (cf. Brown et al., 2009).

A nuestro entender, la existencia de un relieve volcánico intracuencal también tuvo influencia sobre los depósitos de las otras asociaciones de facies. Normalmente, los sistemas fluviales de carga traccional constituyen sucesiones sedimentarias de textura gruesa (sistemas entrelazados gravosos y arenosos) en los que los depósitos de grano fino (arenas muy finas, fangos) son muy subordinados y con frecuencia están ausentes (cf. Miall, 1978; Bluck, 1979; Ramos et al., 1986; Bristow y Best, 1993). En cambio, en la Formación Rancahué se aprecia una notable coexistencia entre los depósitos fluviales de la asociación de facies B y los finos de la asociación C. Es muy posible que la acumulación de estos últimos depósitos se haya visto favorecida por la formación de áreas topográficamente elevadas dentro de la cuenca debidas tanto a la acumulación de lavas basálticas como a lóbulos de materiales volcanoclásticos producidos por movimientos en masa (flujos de detritos, avalanchas, etc.). Estas áreas elevadas habrían delimitado zonas protegidas en las que no pudo implantarse la red de canales fluviales entrelazados. Así, la interestratificación y los pasajes laterales entre depósitos fluviales de baja canalización y depósitos de planicies constituirían un modelo muy particular de sedimentación que resultaría típico de depocentros caracterizados por el desarrollo de relieves volcánicos contemporáneos con la sedimentación.

\section{Flujos gravitacionales de sedimentos y preser- vación del bosque de Rancahué}

El presente estudio ha permitido avanzar en algunos conceptos tafonómicos originales, ya que se ha podido establecer una clara relación entre el desarrollo de facies sedimentarias y la preservación de los leños de una frondosa vegetación boscosa. Las observaciones de campo muestran que la vegetación identificada en la Formación Rancahué arraigó y se desarrolló a partir de suelos cuyas rocas madres fueron sedimentos de grano fino correspondientes a la asociación de facies C. No obstante, los restos de troncos aparecen estrechamente asociados a las otras dos asociaciones de facies, caracterizadas por el dominio de depósitos de textura gruesa.

Por una parte, los troncos preservados in situ se identifican en la asociación de facies A que es el resultado de la acumulación por flujos gravitacionales de sedimentos (Bridge, 2003), del tipo de flujos de detritos, 'debris floods' y avalanchas de detritos. Por otra, los troncos transportados (desarraigados y fragmentados) están incluidos en los depósitos de la asociación de facies B, generados por corrientes fluviales de flujo rápido en las que predominó el transporte y acumulación de carga de lecho.

Es claro que el emplazamiento de sistemas fluviales entrelazados con dominio de flujos tractivos con alto poder erosivo (AF-B) produjo fenómenos de erosión del sustrato a gran escala, y el desarraigo de la vegetación y su remoción, con la consecuente acumulación de los restos de los troncos como parte del relleno de los canales (Fig. 11).

El hecho más paradójico se produce cuando se analiza la relación entre los troncos preservados en posición de vida y la asociación de facies que los aloja, dado que se trata de depósitos de textura muy gruesa que representan una sedimentación proximal en áreas de taludes y del pie de taludes de muy alta energía. No obstante, los flujos gravitacionales de sedimentos inferidos para la formación de esta asociación de facies se caracterizan por una tasa de 


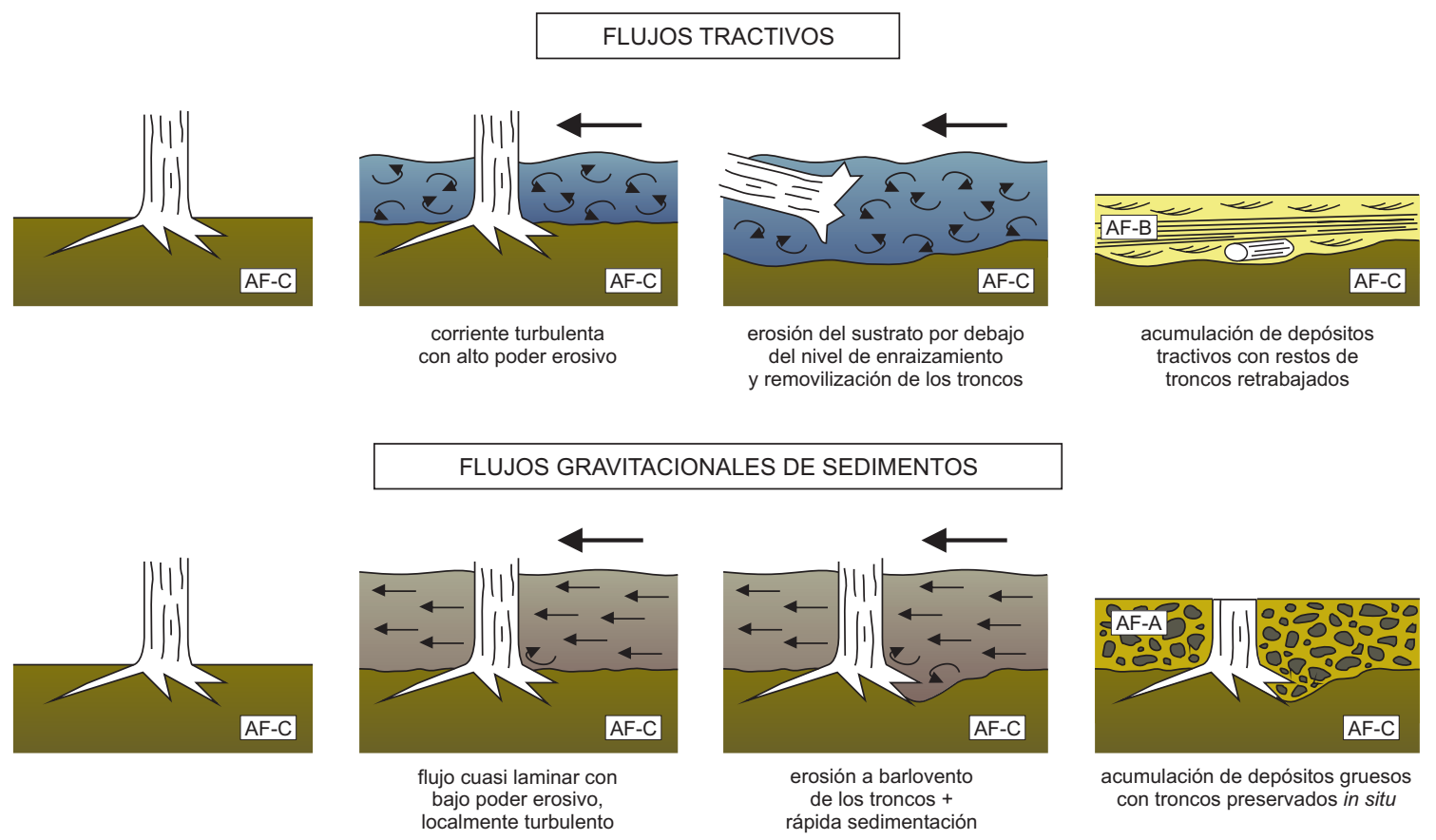

FIG. 11. Diferentes estilos de preservación de los troncos del bosque de la Formación Rancahué en función de los procesos sedimentarios involucrados. Los flujos tractivos de alto poder erosivo retrabajan completamente los troncos, mientras que los flujos gravitacionales de sedimentos, de bajo poder erosivo y alta tasa de sedimentación, preservan los mismos en posición de vida, pese a su alta energía.

sedimentación extremadamente alta y un poder de erosión bastante discreto dado su carácter laminar o cuasi laminar (Bridge, 2003; Brea et al., 2005; Boggs, 2009). Así, es posible que estos procesos hayan producido un rápido soterramiento de los árboles, y aun cuando pudieron contribuir a la destrucción del bosque, también favorecieron la preservación de la porción de los troncos que alcanzó a ser sepultada (Fig. 11).

\section{Conclusiones}

- Se definieron tres asociaciones de facies para los depósitos de la Formación Rancahué en el depocentro de Aluminé que caracterizan la interacción de procesos aluviales y fluviales en un ambiente volcánico.

- La asociación de facies A representa la acumulación en ambientes proximales de altas pendientes a partir de 'debris floods' o flujos hiperconcentrados, avalanchas, deslizamientos y flujos de detritos. La asociación de facies B se asigna al desarrollo de un sistema fluvial de tipo entrelazado, mientras que la asociación de facies $\mathrm{C}$ representa la acumulación de depósitos finos en cuerpos de aguas estancadas y planicies subaéreas con desarrollo de suelos, y en los que periódicamente se produjeron acumulaciones piroclásticas de caída.

- El estudio de facies y arquitectural muestra la interacción de dos sistemas de depositación, uno regional y otro local. El regional corresponde a las asociaciones de facies $\mathrm{B}$ y C y está dominado por depósitos traccionales fluviales con baja canalización, generados en una red imbrífera con áreas de aporte en la Cordillera de los Andes. El sistema local está formado por los depósitos proximales de la asociación de facies A, cuyos detritos han sido aportados por cuerpos volcánicos basálticos que generaron un importante relieve intracuencal. - Un bosque de condiciones climáticas templadas y húmedas se desarrolló al pie de relieves volcánicos intracuencales. La vegetación boscosa preservada en posición de vida se registra en aglomerados y conglomerados monomícticos de la asociación de facies A, habiendo arraigado en depósitos de grano fino de la asociación de facies $\mathrm{C}$ que la 
subyacen. Los restos de troncos transportados se identifican en depósitos de la asociación de facies B generada por corrientes fuertemente erosivas. La preservación in situ de los troncos habría sido favorecida por un rápido sepultamiento, causado por los depósitos volcanoclásticos de la asociación de facies $\mathrm{A}$, caracterizados por una tasa de sedimentación extremadamente alta y un poder de erosión discreto.

\section{Agradecimientos}

Este trabajo fue financiado con fondos del proyecto PIP 5968 (CONICET, Argentina). Los autores agradecen la colaboración de E. Morel, D. Ganuza y L. Martínez por su colaboración durante las tareas de campo. Expresan su reconocimiento a los miembros del Escuadrón 32 'Aluminé' de Gendarmería Nacional Argentina por el apoyo recibido. Expresan asimismo su reconocimiento a dos árbitros anónimos y al editor de la revista por las recomendaciones efectuadas a la versión preliminar de este trabajo.

\section{Referencias}

Allen, J.R.L. 1973. Features of cross-stratified units due to random and other changes in bed forms. Sedimentology 20: 189-202.

Best, J.L.; Ashworth, P.J.; Bristow, C.S.; Roden, J. 2003. Three-dimensional sedimentary architecture of a large, mid-channel sand braid bar, Jamuna River, Bangladesh. Journal of Sedimentary Research 73: 516-530.

Blair, T.C.; McPherson, J.G. 1994. Alluvial fans and their natural distinction from rivers based on morphology, hydraulic processes, sedimentary processes, and facies assemblages. Journal of Sedimentary Research 64: 450-489.

Bluck, B.J. 1979. Structure of coarse grained braided alluvium. Transactions of the Royal Society of Edinburgh 70: 29-46.

Boggs, S. 2009. Petrology of Sedimentary Rocks. Cambridge University Press: 610 p. Cambridge.

Brea, J.D.; Spalletti, L.; Hopwood, H.J.; Spalletti, P. 2005. Conceptos y aplicaciones sobre flujos densos en la hidráulica de ríos. Ingeniería del Agua 12 (3): 189-200.

Brea, M.; Zucol, A.; Morel, E.; Artabe, A.; Franzese, J.; Veiga, G.; Spalletti, L.; Ganuza, D. 2007. Estudios paleobotánicos de la Formación Rancahué (Mioceno) en la provincia del Neuquén, Argentina. In Reunión Anual de Comunicaciones, Asociación Paleontológica Argentina. Ameghiniana Suplemento 44 (4): p. 89R. Buenos Aires.
Brea, M.; Artabe, A.E.; Franzese, J.R.; Morel, E.; Zucol, A.F.; Veiga, G.D.; Spalletti, L.A.; Ganuza, D.G. 2009. Reconstrucción ecológica del bosque fósil in situ de Aluminé (Formación Rancahué, Oligoceno superior), Neuquén, Argentina. In Simposio Argentino de Paleobotánica y Palinología, No. 14. Ameghiniana Suplemento 46 (4): p. 65R. Buenos Aires.

Bridge, J.S. 2003. Rivers and Floodplains; Forms, Processes, and Sedimentary Record. Blackwell: 491 p. Oxford.

Bristow, C.S. 1993. Sedimentology of the Rough Rock: a Carboniferous braided river sheet sandstone in northern England In Braided Rivers (Best, J.L.; Bristow, C.S.; editors). Geological Society, Special Publication 75: 291-304. London.

Bristow, C.S.; Best, J.L. 1993. Braided rivers: Perspectives and probles. In Braided Rivers (Best, J.L.; Bristow, C.S.; editors). Geological Society, Special Publication 75: 1-11. London.

Brown, D.J.; Holohan, E.P.; Bell, B.R. 2009. Sedimentary and volcano-tectonic processes in the British Paleocene Igneous Province: a review. Geological Magazine 146: 326-352.

Cucchi, R.; Leanza, H.A. 2006. Hoja Geológica 3972-IV Junín de los Andes. Provincia del Neuquén. Servicio Geológico Minero Argentino, Boletín 357: 103 p. Buenos Aires.

Fisher, R.V.; Smith, G.A. 1991. Sedimentation in Volcanic Settings. SEPM (Society for Sedimentary Geology), Special Publication 45: 257 p. Tulsa.

Franzese, J.R.; D’Elia, L.; Bilmes, A.; Muravchik, M.; Hernández, M. 2011. Superposición de cuencas extensionales y contraccionales oligo-miocenas en el retroarco andino norpatagónico: la Cuenca de Aluminé, Neuquén, Argentina. Andean Geology 38 (2): 319-334.

Glicken, H. 1991. Sedimentary architecture of large volcanic-debris avalanchers. In Sedimentation in Volcanic Settings (Fisher, R.V.; Smith, G.A.; editors). SEPM (Society for Sedimentary Geology), Special Publication 45: 99-106. Tulsa.

IUGS (International Union of Geological Sciences). 2012. International Chronostratigraphic Chart. International Commission on Stratigraphy. www.stratigraphy.org (accessed 07/02/2013).

Leleu, S.; van Lanen, X.M.T.; Hartley, A.J. 2010. Controls on the architecture of a Triassic sandy fluvial system, Wolfville Formation, Fundy Basin, Nova Scotia, Canada: implications for the interpretation and correlation of ancient fluvial successions. Journal of Sedimentary Research 80: 867-883. 
Lunt, L.A.; Bridge, J.S. 2004. Evolution and deposits of a gravelly braid bar. Sgavanirktok River, Alaska. Sedimentology 51: 415-432.

Lunt, L.A.; Bridge, J.S.; Tye, R.S. 2004. A quantitative, three-dimensional depositional model of gravelly braided rivers. Sedimentology 51: 377-414.

Mader, N.K.; Redfern, J. 2011. A sedimentological model for the continentalk Upper Triassic Tadrart Ouadou Sandstone Member: recording an interplay of climate and tectonics (Argana Valley; South-west Morocco). Sedimentology 58: 1247-1282.

Masson, D.G.; Watts, A.B.; Gee, M.J.R.; Urgeles, R.; Mitchell, N.C.; Le Bas, T.P.; Canals, M. 2002. Slope failures on the flanks of the western Canary Islands. Earth Science Reviews 57: 1-35.

Melnick, D.; Echtler, H. 2006. Morphotectonic and geologic digital map compilations of the Routh-central Andes $\left(36-42^{\circ} \mathrm{S}\right)$. In The Andes-Active Subduction Orogeny (Oncken, O.; Chong, G.; Franz, G.; Giese, P.; Götze, H.; Ramos, V.A.; Strecker, M.; Wigger, P.; editors). Frontiers in Earth Sciences 1. Springer: 582 p. Berlin.

Miall, A.D. 1978. Lithofacies types and vertical profile models in braided river deposits: a summary. In Fluvial Sedimentology (Miall, A.; editor). Canadian Society of Petroleum Geologists, Memoir 5: 597-604. Calgary.

Moore, J.G.; Bryan, W.B.; Beeson M.H.; Normark, W.R. 1995. Giant blocks in the south Kona Island landslide, Hawaii. Geology 23: 125-128.

Nemeth, K.; Cronin, S.J. 2007. Syn- and post-eruptive erosion, gully formation, and morphological evolution of a tephra ring in tropical climate erupted in 1913 in West Ambrym, Vanuatu. Geomorphology 86: 115-130.

Palmer, B.A.; Neall, V.E. 1991. Contrasting lithofacies architecture in ring-plain deposits related to edifice construction and destruction, the Quaternary Stratford and Opunake Formations, Egmont Volcano, New Zealand. Sedimentary Geology 74: 71-88.

Palmer, B.A.; Alloway, B.V.; Neall, V.E. 1991. Volcanic debris-avalanche deposits in New Zealand-lithofacies organization in unconfined, wet-avalanche flows. In Sedimentation in Volcanic Settings (Fisher, R.V.; Smith, G.A.; editors). SEPM (Society for Sedimentary Geology), Special Publication 45: 88-98. Tulsa.

Radic, J.P. 2010. Las cuencas cenozoicas y su control en el volcanismo de los Complejos Nevados de Chillán y Copahue-Callaqui (Andes del Sur, 36-39' S). Andean Geology 37: 220-246.

Ramos, A.; Sopeña, A.; Pérez Arlucea, M. 1986. Evolution of Buntsandstein fluvial sedimentation in the northwest
Iberian Ranges (Central Spain). Journal Sedimentary Petrology 56: 862-875.

Reubi, O.; Roy, P.S.; White, J.D.L. 2005. Debris avalanche deposits associated with large igneous province volcanism: an example from the Mawson Formation, central Allan Hills, Antarctica. Geological Society of America, Bulletin 117: 1615-1628.

Schumm, S.A. 1981. Evolution and response of the fluvial system; sedimentologic implications. In Recent and Ancient Nonmarine Depositional Environments (Ethridge, F.G.; Flores, R.M.; editors). SEMP (ociety for Sedimentary Geology), Special Publication 31: 19-29. Tulsa.

Schumm, S.A. 1985. Patterns of alluvial rivers. Annual Review of Earth and Planetary Sciences 13: 5-27.

Smith, G.A. 1991. Facies sequences and geometries in continental volcaniclastic sediments. In Sedimentation in Volcanic Settings (Fisher, R.V.; Smith, G.A.; editors). SEPM (Society for Sedimentary Geology), Special Publication 45: 10-25. Tulsa.

Smith, N.D. 1970. The braided stream depositional environment: comparison of the Platte River with some Silurian clastic rocks, North Central Appalachians. Geological Society of America, Bulletin 81: 2993-3014.

Smith, S.A. 1990. The sedimentology and accretionary styles of an ancient gravel bed stream: the Budleigh Salterton Pebble beds (Lower Triassic), southwest England. Sedimentary Geology 67: 199-219.

Steel, R.J.; Thompson, D.J. 1983. Structures and textures in Triassic braided stream conglomerates ('Bunter' Pebble Beds) in the Sherwood Sandstone Group, North Staffordshire, England. Sedimentology 30: 341-368.

Tanner, L.H.; Hubert, J.F. 1991. Basalt breccias and conglomerates in the Lower Jurassic McCoy Brook Formation, Fundy Basin, Nova Scotia: differentiation of talus and debris-flow deposits. Journal of Sedimentary Petrology 61: 15-27.

Teruggi, M.E.; Mazzoni, M.M.; Spalletti, L.A.; Andreis, R.R. 1978. Rocas Piroclásticas. Interpretación y Sistemática. Asociación Geológica Argentina, Publicaciones Especiales, Serie B (Didáctica y Complementaria) 5: 1-36. Buenos Aires.

Turner, J.C.M. 1965. Estratigrafía de Aluminé y adyacencias. Asociación Geológica Argentina, Revista 20: 153-164.

Turner, J.C.M. 1973. Descripción geológica de la Hoja 37 a-b, Junín de los Andes, provincia del Neuquén. Servicio Nacional Minero Geológico, Boletín 138: 1-86. Buenos Aires. 
Ui, T. 1983. Volcanic dry avalanche deposits-Identification and comparison with nonvolcanic debris stream deposits. Journal of Volcanology and Geothermal Research 18: 135-150.

White, J.D.L.; Riggs, N. 2001. Volcaniclastic Sedimentation in Lacustrine Settings. In International Association of Sedimentologists, Special Publication 30: 309 p. Oxford.
Wilford, D.J.; Sakals, M.E.; Innes, J.L.; Sidle, R.C. 2005. Fans with forests: contemporary hydrogeomorphic processes on fans with forests in west central British Columbia, Canada. In Alluvial Fans: Geomorphology, Sedimentology, Dynamics (Harvey, A.M.; Mather, A.E.; Stokes, M.; editors). Geological Society, Special Publication 251: 25-40. London.

Manuscript received: August 29, 2012; revised/accepted: March 15, 2013; available online: March 18, 2013. 